\title{
Ductal carcinoma in situ of breast: detection and treatment pattern in Hong Kong
}

\author{
TK Yau *, Amy Chan, Polly SY Cheung
}

This article was published on 24 Oct 2016 at www.hkmj.org.

\section{A B S T R A C T}

Introduction: The treatment of ductal carcinoma in situ has been widely reported in the western and other Asian countries, but the relevant data in Hong Kong are relatively limited. This study aimed to evaluate the latest detection and treatment pattern for ductal carcinoma in situ in Hong Kong so as to guide planning of future service provision.

Methods: This was a retrospective case series study. A total of 573 patients who registered with the Hong Kong Breast Cancer Registry, and were diagnosed and treated in Hong Kong from January 2001 to December 2011 were reviewed.

Results: Compared with invasive breast cancer patients, patients with ductal carcinoma in situ were younger (median, 48.6 vs 50.3 years; $\mathrm{P}<0.001$ ), had a higher education level $(P<0.001)$, had a higher total monthly family income $(\mathrm{P}<0.001)$, and had more common breast-screening habits $(\mathrm{P}<0.001)$. Significantly more patients with ductal carcinoma in situ underwent breast-conserving surgery than their invasive cancer counterparts $(55.8 \%$ vs $36.7 \%$; $\mathrm{P}<0.001)$. The percentage of screen-detected ductal carcinoma in situ was relatively lower than that reported in other studies, but was still much higher than that in invasive breast cancer patients $(29.0 \%$ vs

carcinoma in situ tended to choose a private hospital instead of a public hospital for treatment $(\mathrm{P}=0.05)$ and to undergo breast-conserving surgery $(\mathrm{P}=0.02)$. With a median follow-up of 3 years, the crude local recurrence rate after mastectomy and breastconserving surgery was $0.4 \%$ and $3.3 \%$, respectively; $44 \%$ of recurrent tumours had developed invasive components. No regional recurrence, distant recurrence, or cancer-related deaths were recorded.

Conclusions: In the absence of a population-based breast screening programme in Hong Kong, ductal carcinoma in situ is more frequently found in the higher social classes and managed in the private sector. The clinical outcome of ductal carcinoma in situ is excellent and more than half of the patients can be successfully managed with breast-conserving surgery.

\section{Hong Kong Med J 2017;23:19-27}

DOI: 10.12809/hkmj154754

TK Yau *, FHKCR, FHKAM (Radiology)

A Chan, BSc, MPhil

PSY Cheung, FRACS, FHKAM (Surgery)

Hong Kong Breast Cancer Foundation, 22/F, Jupiter Tower, No. 9, Jupiter Street North Point, Hong Kong

4.7\%; $\mathrm{P}<0.001)$. Screen-detected patients with ductal * Corresponding author: research@hkbcf.org

New knowledge added by this study

- This is the largest comprehensive study to evaluate the pattern of care for patients with ductal carcinoma in situ (DCIS) in Hong Kong.

Implications for clinical practice or policy

Further studies are needed to evaluate the long-term clinical outcome of DCIS in Hong Kong.

\section{Introduction}

Ductal carcinoma in situ (DCIS) of the breast is a non-invasive, pre-cancerous lesion that was uncommon prior to the widespread use of mammography (MMG) screening; it is traditionally treated by mastectomy (MTX) with cure rates approaching $100 \%{ }^{1}$ The high incidence rate and mortality rate of breast cancer in women ${ }^{2}$ has led to the setting up of population-based breast cancer screening programmes by government in 34 countries..$^{3-6}$ One of the results of the popularity of breast screening is the rise in the detected incidence of DCIS. ${ }^{7}$ Some western studies revealed that DCIS constituted approximately $10 \%$ to $40 \%$ of lesions detected by MMG screening. ${ }^{8}$ In Asia, following the pilot Singapore Breast Screening Project, the diagnosis of DCIS also increased markedly. ${ }^{9}$ Screendetected DCIS showed a better clinical profile such as smaller size and higher chance of being treated by breast-conserving surgery (BCS).$^{9}$ Early detection of breast cancer at this stage offers the best opportunity for curative treatment. ${ }^{10}$

The treatment of DCIS has been widely studied and reported in the western and other Asian countries. ${ }^{11-16}$ Although there have been no prospective randomised trials to compare MTX with BCS for DCIS, BCS has been widely accepted as an alternative treatment, ${ }^{17}$ especially for small mammographically detected lesions. In Hong Kong, however, data on DCIS are relatively limited. 


\section{原位乳癌在香港的偵測和治療模式} 游子覺、陳安薇、張淑儀

引言：原位乳癌的治療在西方和其他亞洲國家已進行廣泛研究, 香港 的相關數據卻相對有限。本研究旨在評估原位乳癌在香港最新的檢測 和治療模式, 為未來服務計劃提供指引。

方法: 本回顧性病例系列研究的對象是於香港乳癌資料庫內的女性 患者。2001年1月至2011年12月期間共有573名患者被診斷並接受治 療。

結果：與入侵性乳癌患者比較, 患有原位乳癌的患者較年輕（年齡中 位數為48.6歲比50.3歲； $\mathrm{P}<0.001)$ 、有較高教育水平 $(\mathrm{P}<0.001)$

有較高家庭總收入（ $\mathrm{P}<0.001)$ 和較高進行乳房檢查習慣率 $(\mathrm{P}<0.001)$ 。此外, 她們接受乳房保留手術的比例較高（ $55.8 \%$ 比 $36.7 \% ; \mathrm{P}<0.001)$ 。雖然從篩檢中得悉患有原位乳癌的比率與 其他研究比較相對低, 但仍然較入侵性乳癌患者為高 $(29.0 \%$ 比 $4.7 \% ； \mathrm{P}<0.001 ） 。$ 從篩檢中得悉患有原位乳癌的患者較傾向選擇私 家醫院而非公立醫院作治療（ $\mathrm{P}=0.05 ）$, 且較多接受乳房保留手術 $(\mathrm{P}=0.02) \circ$ 跟進期中位數為3年的結果顯示, 乳房切除術後局部區 域性復發率為 $0.4 \%$, 而乳房保留手術復發率則為 $3.3 \%$ 。有 $44 \%$ 的復發 腫瘤發展為入侵性乳癌。研究結果並無局部復發、遠端復發或與癌症 相關的死亡病例。

結論：香港沒有以人口為基礎的乳癌篩查計劃, 原位乳癌較易發現於 較高社會階層的人口, 亦有較多患者於私家醫院作治療。原位乳癌的 臨床結果極佳, 而且超過一半患者可通過乳房保留手術成功治療。

The Hong Kong Cancer Registry has only started to release basic data of annual incidence and age distribution of DCIS since 2009. In 2012,3508 women in Hong Kong were diagnosed with invasive breast cancer and 477 women were diagnosed with DCIS ${ }^{18}$ that constituted only $12.0 \%$ of the total number of breast cancer patients diagnosed. This incidence of DCIS was relatively low compared with the $20.7 \%$ in the United States. ${ }^{14}$ Since our presentation and treatment pattern of DCIS are likely different to that in other countries, it is necessary to examine the particular pattern of care of DCIS in Hong Kong to better understand this disease.

The aim of this study was to evaluate the latest detection and treatment pattern for DCIS in Hong Kong so as to guide planning of future service provision.

\section{Methods}

The Hong Kong Breast Cancer Registry (HKBCR) was first established in 2007 by the Hong Kong Breast Cancer Foundation as a data collection and monitoring system for breast cancer in Hong Kong. The HKBCR aims to collect and analyse data from all Hong Kong breast cancer patients to obtain comprehensive information about demographics, risk exposures, treatments, clinical outcomes, and psychosocial impact on patients. It is the first population-wide, cancer-specific registry for breast cancer patients in Hong Kong and has been a member of the International Association of Cancer Registries since 2011, providing international standard data management and accuracy.

Between 2008 and 2011, a total of 5393 patients with a history of in-situ or invasive breast cancers were registered with the HKBCR on a voluntary basis. Of these patients, 2539 (47.1\%) and 2854 (52.9\%) were recruited from private clinics or hospitals and public hospitals, respectively. Demographics and risk exposure data were collected from these patients by questionnaire; clinical characteristics, detection methods, diagnostic methods, disease stage, histopathological profile, treatment modalities, and clinical outcome data were extracted from their medical records. ${ }^{19}$ Data analysis was carried out in December 2014.

Inclusion criteria for this study were as follows: female patient being diagnosed and treated in Hong Kong from January 2001 to December 2011; pure DCIS with no invasive element in ipsilateral or contralateral breast at the time of diagnosis; definitive surgery performed; complete pathology details available; if axillary node sampling/dissection was performed, the nodal status must be negative; and no prior neoadjuvant treatment administered. Overall, 573 patients, including 16 synchronous patients with bilateral DCIS, from the HKBCR fulfilled the above criteria for further study.

For comparison purposes, the records of female patients with invasive breast cancer diagnosed and treated in Hong Kong during the same period were also extracted from HKBCR. Altogether, 1611 invasive breast carcinoma patients with 20 synchronous bilateral patients were retrieved for data analysis.

In this study, local recurrence was defined as the reappearance of cancer, invasive or non-invasive, in the treated breast or chest wall before or at the time of regional or distant metastases. All events were measured from the date of the definitive surgery. Descriptive statistics were used to describe the patterns of demographic and pathological features. Statistical significance was tested using Chi squared tests for categorical variables. The Kaplan-Meier method was applied to analyse the local recurrence estimation. All statistical tests were two-sided and performed at the 0.05 level of significance (P value). The Statistical Package for the Social Sciences (Windows version 19.0; SPSS Inc, Chicago [IL], US) was used for all statistical analyses.

The project was approved by respective Institutional Review Board and Ethics Committee of the following hospitals: Hong Kong Sanatorium \& Hospital, Hong Kong Baptist Hospital, Hong Kong Adventist Hospital, Princess Margaret Hospital, United Christian Hospital, Prince of Wales Hospital, Queen Mary Hospital, Pamela Youde Nethersole Eastern Hospital, Pok Oi Hospital, North District 
Hospital, Tuen Mun Hospital, and Yan Chai Hospital. All participants provided written informed consent.

\section{Results}

Of the 573 patients with DCIS of breast, the majority (74.9\%) were diagnosed and treated between 2006 and 2011. A similar distribution was found in the 1611 patients with invasive breast cancer.

Table 1 compares the demographic characteristics of DCIS and invasive breast cancer patients. The results indicate that DCIS patients were significantly younger (median, 48.6 vs 50.3 years; $\mathrm{P}<0.001$ ), had a higher education level (matriculation or above, $34.0 \%$ vs $15.0 \% ; \mathrm{P}<0.001$ ), were more likely to be working (61.1\% vs $55.8 \%$; $\mathrm{P}<0.001)$, and had a higher total monthly family income of $\mathrm{HK} \$ 30000$ or above $(32.6 \%$ vs $16.6 \% ; \mathrm{P}<0.001)$. More DCIS patients had regular breast screening habits in the form of self-examination (monthly: $23.6 \%$ vs $21.8 \%$; $\mathrm{P}<0.001$ ), clinical breast examination (yearly: $41.5 \%$ vs $27.3 \% ; \mathrm{P}<0.001$ ), MMG screening (yearly: $24.1 \%$ vs $10.6 \% ; \mathrm{P}<0.001$ ), and breast ultrasound screening (yearly: $20.9 \%$ vs $10.2 \% ; \mathrm{P}<0.001$ ). Patients with DCIS had a much higher chance of being asymptomatic at diagnosis (ie screen-detected) than their invasive breast cancer counterparts ( $29.0 \%$ vs $4.7 \% ; \mathrm{P}<0.001)$. Significantly more DCIS patients underwent BCS than their invasive cancer counterparts $(55.8 \%$ vs $36.7 \% ; \mathrm{P}<0.001$ ). Among those treated by BCS, DCIS patients had a similar chance of receiving adjuvant radiotherapy as the invasive cancer patients (94.1\% vs $93.8 \%)$. As expected, only very few (8.7\%) DCIS patients required adjuvant radiotherapy after MTX. Although DCIS patients do not require systemic adjuvant therapy, some may be prescribed hormone therapy as chemoprevention. In our study, only a small percentage of DCIS patients received hormone therapy and the pattern was similar after BCS or MTX (19.4\% after BCS and $17.0 \%$ after MTX; $\mathrm{P}<0.001)$.

Table 2 shows the patient demographics, and clinical and pathological characteristics of screen-detected (asymptomatic) and self-detected (symptomatic) DCIS in Hong Kong. There was no significant difference in the median age between these subgroups ( 49.1 vs 48.5 years; $\mathrm{P}=0.23$ ). The screen-detected subgroup had a significantly higher education level (matriculation or above, $42.7 \%$ vs 29.6\%; $\mathrm{P}=0.01$ ), higher total monthly family income of $\mathrm{HK} \$ 30000$ or above ( $45.7 \%$ vs $26.8 \% ; \mathrm{P}=0.01$ ), and underwent more regular clinical breast examination (yearly: $49.4 \%$ vs $35.5 \%$; $\mathrm{P}<0.001$ ), MMG (every 2 years: $22.0 \%$ vs $7.0 \% ; \mathrm{P}<0.001$ ), and breast ultrasound screening (every 2 years: $11.6 \%$ vs $3.4 \% ; \mathrm{P}<0.001$ ).

Among the DCIS patients, 28.6\% (164/573) were screen-detected: since MMG screening is not usually recommended in younger women, only $14.5 \%$ (11/76) of DCIS in patients aged below 40 years were screen-detected compared with $34.3 \%(148 / 431)$ in patients aged above 40 years. Irrespective of the type of presentation, two thirds or more of DCIS patients chose to have surgery at a private hospital and the screen-detected subgroup had an even higher tendency to do so ( $74.4 \%$ vs $65.6 \% ; \mathrm{P}=0.05$ ). Although there was a trend of finding smaller lesions in the screen-detected subgroup, there was no significant difference between the two subgroups in tumour size (median: $1.6 \mathrm{~cm}$ vs $2.0 \mathrm{~cm} ; \mathrm{P}=0.14$ ). Despite this finding, screen-detected DCIS patients had a higher chance of being treated by BCS than symptomatic patients ( $65.9 \%$ vs $51.4 \% ; \mathrm{P}=0.02)$ [Table 2].

Among 573 patients with DCIS, clinical outcome data were available for 487 patients only. With a median follow-up of 3.1 (range, 0.5-10.9) years, the early clinical outcome was very good and compatible with other series. The overall crude local recurrence rate in DCIS patients was 3.9\% (19 in 487 patients) and, as expected, there was a significant difference between MTX and BCS patients $(0.4 \%$ vs $3.3 \%$ ) [Table 3]. Of the 18 patients with known pathology at recurrence, eight (44.4\%) had developed invasive components. Of the 16 BCS patients, 11 (68.8\%) underwent salvage MTX at recurrence. Overall, by 6 years, the projected local recurrence rates after BCS were similar for DCIS patients and invasive breast cancer patients $(\log$ rank, $\mathrm{P}=0.21$; Fig). No regional recurrence, distant recurrence, or cancer-related death were observed in the DCIS patients.

\section{Discussion}

Ductal carcinoma in situ was relatively uncommon in western countries until the widespread use of mass breast screening. There is strong evidence that the recent rise in DCIS incidence is related to the popularity of breast screening. Since there is no government-funded breast screening programme in Hong Kong, our study showed that only $29.0 \%$ of the DCIS in Hong Kong was first detected by screening, significantly lower than the $80 \%$ screen-detected rate in DCIS of other studies. ${ }^{20-24}$ Our data showed that these DCIS patients in general had a higher monthly family income and higher level of education than their invasive cancer counterparts and this may contribute to their higher acceptance of self-funded breast screening, higher breast cancer awareness, and hence better chance of detecting breast cancer at an early stage. Not surprisingly, the use of BCS was also significantly more popular in the DCIS patients compared with their invasive cancer counterparts (55.8\% vs $36.7 \% ; \mathrm{P}<0.001$ ). Our results were also consistent with a previous local study that reported the performance of opportunistic breast screening in local well women clinics and showed that breast screening could achieve a higher cancer detection rate and detect the cancer at an early stage. ${ }^{25}$ 
TABLE I. Comparison of patient demographic features and clinical treatment between DCIS and invasive breast cancer patients

\begin{tabular}{|c|c|c|c|}
\hline & \multicolumn{2}{|c|}{ No. $(\%)$ of patients* } & \multirow[t]{2}{*}{$\mathbf{P}$ valuet } \\
\hline & DCIS (n=573) & Invasive $(n=1611)$ & \\
\hline Age (years) at diagnosis & & & 0.06 \\
\hline$<40$ & $79(13.8)$ & $177(11.0)$ & \\
\hline$\geq 40$ & $477(83.2)$ & $1399(86.8)$ & \\
\hline Not known & $17(3.0)$ & $35(2.2)$ & \\
\hline Median (range) & $48.6(26.9-80.2)$ & $50.3(18.8-91.1)$ & $<0.001$ \\
\hline Marital status & & & 0.03 \\
\hline Single & $90(15.7)$ & $193(12.0)$ & \\
\hline Married & $420(73.3)$ & $1229(76.3)$ & \\
\hline Others (divorced / widowed) & $44(7.7)$ & $155(9.6)$ & \\
\hline Not known & $19(3.3)$ & $34(2.1)$ & \\
\hline Education level & & & $<0.001$ \\
\hline Primary or below & $112(19.5)$ & $529(32.8)$ & \\
\hline Secondary & $244(42.6)$ & 795 (49.3) & \\
\hline Matriculation or above & $195(34.0)$ & $241(15.0)$ & \\
\hline Not known & $22(3.8)$ & $46(2.9)$ & \\
\hline Work status & & & $<0.001$ \\
\hline Working & $350(61.1)$ & $899(55.8)$ & \\
\hline Non-working (housewife, retired, etc) & $182(31.8)$ & $655(40.7)$ & \\
\hline Not known & $41(7.2)$ & $57(3.5)$ & \\
\hline Family history of breast cancer & & & 0.05 \\
\hline 1st Degree & $62(10.8)$ & $146(9.1)$ & \\
\hline 2nd Degree & $31(5.4)$ & $60(3.7)$ & \\
\hline No family history & $461(80.5)$ & $1377(85.5)$ & \\
\hline Not known & $19(3.3)$ & $28(1.7)$ & \\
\hline Total monthly family income (HK\$) & & & $<0.001$ \\
\hline$<10000$ & $64(11.2)$ & $205(12.7)$ & \\
\hline $10000-29999$ & $131(22.9)$ & $453(28.1)$ & \\
\hline$\geq 30000$ & $187(32.6)$ & $267(16.6)$ & \\
\hline Not known & $191(33.3)$ & $686(42.6)$ & \\
\hline \multicolumn{4}{|l|}{ Breast screening habits } \\
\hline Self-examination & & & $<0.001$ \\
\hline Never & $143(25.0)$ & $683(42.4)$ & \\
\hline Occasional (less frequent than monthly) & $248(43.3)$ & $515(32.0)$ & \\
\hline Monthly & $135(23.6)$ & $352(21.8)$ & \\
\hline Not known & $47(8.2)$ & $61(3.8)$ & \\
\hline Clinical examination & & & $<0.001$ \\
\hline Never & $138(24.1)$ & $775(48.1)$ & \\
\hline Occasional (less frequent than every 2 years) & $96(16.8)$ & $233(14.5)$ & \\
\hline Every 2 years & $57(9.9)$ & $107(6.6)$ & \\
\hline Yearly & $238(41.5)$ & $440(27.3)$ & \\
\hline Not known & $44(7.7)$ & 56 (3.5) & \\
\hline
\end{tabular}

Abbreviations: DCIS = ductal carcinoma in situ; MMG = mammography; MRI = magnetic resonance imaging; USG = breast ultrasound screening

* Unless otherwise stated; because of rounding, not all percentages total 100

+ Chi squared test 
TABLE I. (cont'd)

\begin{tabular}{|c|c|c|c|}
\hline & \multicolumn{2}{|c|}{ No. $(\%)$ of patients* } & \multirow[t]{2}{*}{$\mathbf{P}$ value } \\
\hline & DCIS ( $n=573)$ & Invasive $(n=1611)$ & \\
\hline Mammography screening & & & 0.001 \\
\hline Never & $236(41.2)$ & $1149(71.3)$ & \\
\hline Occasional (less frequent than every 2 years) & $88(15.4)$ & $160(9.9)$ & \\
\hline Every 2 years & $67(11.7)$ & $75(4.7)$ & \\
\hline Yearly & $138(24.1)$ & $170(10.6)$ & \\
\hline Not known & $44(7.7)$ & $57(3.5)$ & \\
\hline Ultrasound screening & & & $<0.001$ \\
\hline Never & $246(42.9)$ & $1160(72.0)$ & \\
\hline Occasional (less frequent than every 2 years) & $88(15.4)$ & $139(8.6)$ & \\
\hline Every 2 years & $33(5.8)$ & $44(2.7)$ & \\
\hline Yearly & $120(20.9)$ & $165(10.2)$ & \\
\hline Not known & $86(15.0)$ & $103(6.4)$ & \\
\hline Presenting symptoms & & & $<0.001$ \\
\hline Asymptomatic & $166(29.0)$ & $75(4.7)$ & \\
\hline Screening by MMG & $136(81.9)$ & $25(33.3)$ & \\
\hline Screening by USG & $25(15.1)$ & $13(17.3)$ & \\
\hline Screening by MRI & $3(1.8)$ & 0 & \\
\hline Not known & $2(1.2)$ & $37(49.3)$ & \\
\hline Symptomatic & $380(66.3)$ & $1385(86.0)$ & \\
\hline Palpable breast mass & $296(77.9)$ & $1339(96.7)$ & \\
\hline Nipple discharge & $74(19.5)$ & $20(1.4)$ & \\
\hline Others (nipple retraction, pain) & $29(7.6)$ & $72(5.2)$ & \\
\hline Not known & $27(4.7)$ & $151(9.4)$ & \\
\hline Type of breast surgery & & & $<0.001$ \\
\hline Breast-conserving surgery & $320(55.8)$ & $592(36.7)$ & \\
\hline With radiotherapy & $301(94.1)$ & $555(93.8)$ & \\
\hline Without radiotherapy & $11(3.4)$ & $29(4.9)$ & \\
\hline Radiotherapy not known & $8(2.5)$ & $8(1.4)$ & \\
\hline Mastectomy & $253(44.2)$ & 1019 (63.3) & \\
\hline With radiotherapy & $22(8.7)$ & $522(51.2)$ & \\
\hline Without radiotherapy & $221(87.4)$ & $480(47.1)$ & \\
\hline Radiotherapy not known & $10(4.0)$ & $17(1.7)$ & \\
\hline
\end{tabular}

In contrast, the profile of screen-detected and self-detected (ie symptomatic) DCIS patients showed more similarities than differences. The overall tumour size was not significantly different between these subgroups, although lesions of $>2 \mathrm{~cm}$ were less common in the screen-detected patients (34.8\% vs $43.0 \% ; \mathrm{P}=0.12)$. Since there is no populationbased breast screening programme in Hong Kong, these opportunistic breast screenings performed in various laboratories may have inherent limitations. Overseas studies have shown a considerably higher sensitivity in organised population-based screening than in opportunistic screening, ${ }^{24}$ although a largescale local self-referred breast screening centre reported comparable performance. ${ }^{25}$

Our study showed a high acceptance of BCS for management of DCIS in Hong Kong and nearly all
(94.1\%) BCS patients also underwent postoperative radiotherapy. Although prior randomised studies have demonstrated the benefit of postoperative radiotherapy in reducing both invasive and noninvasive recurrence of DCIS after BCS, much effort has been put into identifying a low-risk subgroup in whom postoperative radiotherapy can be safely omitted. ${ }^{26}$ The Van Nuys prognostic index (VNPI) - a retrospectively derived risk classification that combines tumour size, margin width, and pathological classification-was developed to select this low-risk group. ${ }^{27}$ Nonetheless, perhaps due to contradictory findings from other studies that reported a much higher local failure rate in the VNPI low-risk subgroup ${ }^{28}$ it is apparent that most clinicians in Hong Kong had reservations when applying the VNPI to their DCIS patients. 
TABLE 2. Comparison of clinical and pathological characteristics of DCIS patients between screen-detected and self-detected methods

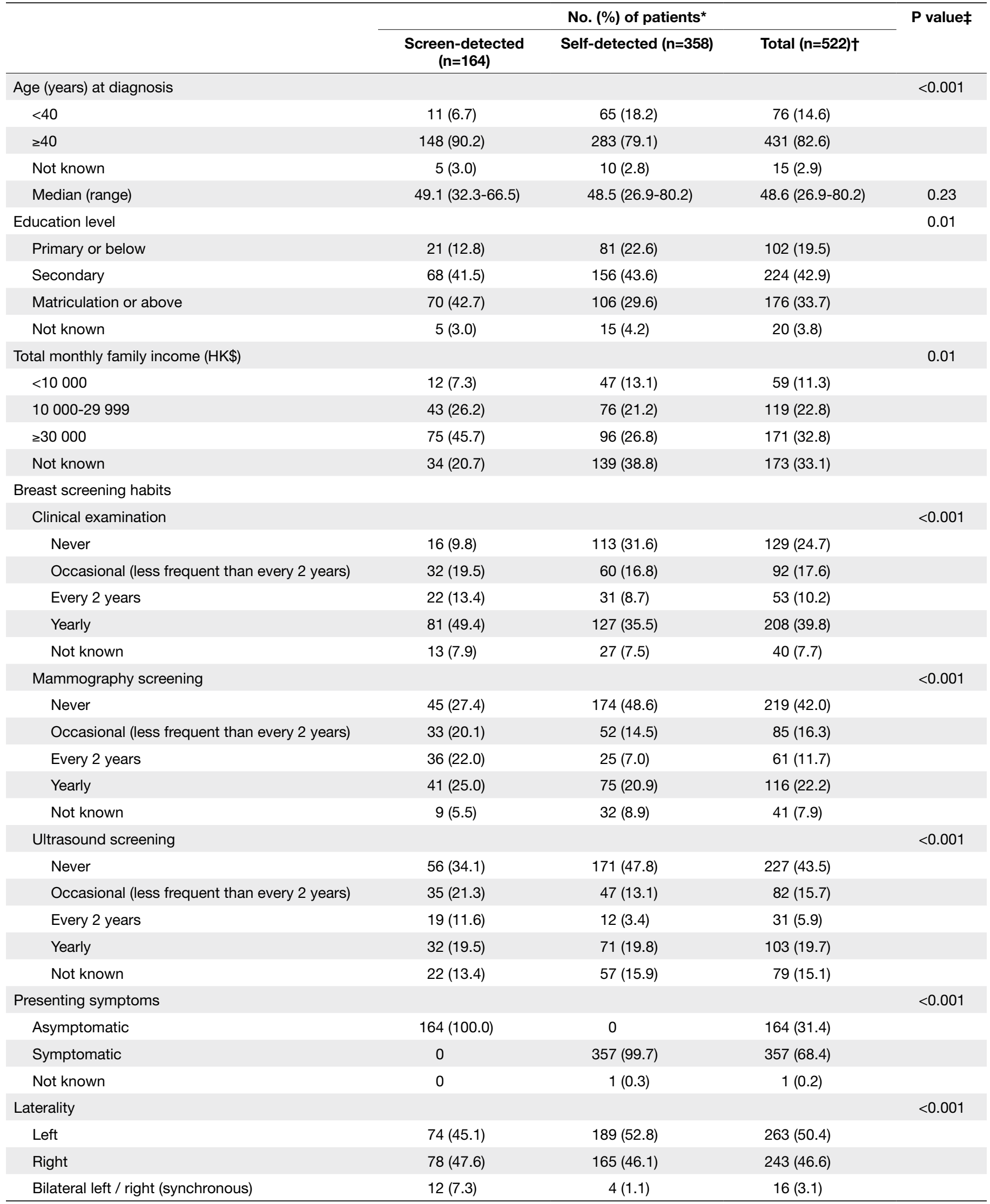

Abbreviations: $\mathrm{DClS}=$ ductal carcinoma in situ; $\mathrm{ER}$ = oestrogen receptor; $\mathrm{PR}$ = progesterone receptor

* Unless otherwise stated; because of rounding, not all percentages total 100

+ Of the 573 patients in this study, only 522 had known data on detection method

$\ddagger$ Chi squared test 
TABLE 2. (cont'd)

\begin{tabular}{|c|c|c|c|c|}
\hline & \multicolumn{3}{|c|}{ No. $(\%)$ of patients* } & \multirow[t]{2}{*}{$\mathbf{P}$ value $\neq$} \\
\hline & $\begin{array}{l}\text { Screen-detected } \\
(n=164)\end{array}$ & Self-detected $(n=358)$ & Total $(n=522) \dagger$ & \\
\hline Size of tumour (cm) & & & & 0.12 \\
\hline$\leq 1.00$ & $53(32.3)$ & $74(20.7)$ & $127(24.3)$ & \\
\hline $1.01-2.00$ & $45(27.4)$ & $103(28.8)$ & $148(28.4)$ & \\
\hline$>2.00$ & $57(34.8)$ & $154(43.0)$ & $211(40.4)$ & \\
\hline Not known & $9(5.5)$ & $27(7.5)$ & $36(6.9)$ & \\
\hline Median (range) & $1.6(0.2-9.0)$ & $2.0(0.1-8.5)$ & $1.9(0.1-9.0)$ & 0.14 \\
\hline Venue of definitive surgery & & & & 0.05 \\
\hline Private hospital & $122(74.4)$ & $235(65.6)$ & $357(68.4)$ & \\
\hline Public hospital & $42(25.6)$ & $123(34.4)$ & $165(31.6)$ & \\
\hline Type of surgery & & & & 0.02 \\
\hline Breast-conserving surgery & $108(65.9)$ & $184(51.4)$ & $292(55.9)$ & \\
\hline Mastectomy & $56(34.1)$ & $174(48.6)$ & $230(44.1)$ & \\
\hline Final resection margin status & & & & 0.06 \\
\hline Margin clear & $84(51.2)$ & $179(50.0)$ & $263(50.4)$ & \\
\hline$\leq 2 \mathrm{~mm}$ (margin clear) & $15(17.9)$ & $46(25.7)$ & $61(23.2)$ & \\
\hline >2 mm (margin clear) & $34(40.5)$ & $48(26.8)$ & $82(31.2)$ & \\
\hline Distance unknown & $35(41.7)$ & $85(47.5)$ & $120(45.6)$ & \\
\hline Margin involved & $6(3.7)$ & $8(2.2)$ & $14(2.7)$ & \\
\hline Not known & $74(45.1)$ & $171(47.8)$ & 245 (46.9) & \\
\hline ER or PR positive & & & & 0.39 \\
\hline No & $26(15.9)$ & $60(16.8)$ & $86(16.5)$ & \\
\hline Yes & $114(69.5)$ & $210(58.7)$ & $324(62.1)$ & \\
\hline Not known & 24 (14.6) & 88 (24.6) & $112(21.5)$ & \\
\hline
\end{tabular}

TABLE 3. Clinical outcome of patients with ductal carcinoma in situ $(n=487)$

\begin{tabular}{|c|c|}
\hline Clinical outcome & Data \\
\hline \multicolumn{2}{|l|}{ Follow-up period (years) } \\
\hline Mean & 3.7 \\
\hline Median & 3.1 \\
\hline Range & $0.5-10.9$ \\
\hline \multicolumn{2}{|l|}{ Local recurrence, No. (\%) } \\
\hline No & $468(96.1)$ \\
\hline Yes & $19(3.9)$ \\
\hline Breast (after breast-conserving surgery) & $16(3.3)$ \\
\hline Chest wall (after mastectomy) & $2(0.4)$ \\
\hline Not known & $1(0.2)$ \\
\hline
\end{tabular}

Although tamoxifen after local excision for DCIS has been shown to reduce the risk of recurrent DCIS in the ipsilateral breast (hazard ratio $=0.75 ; 95 \%$ confidence interval [CI], 0.61-0.92) and contralateral breast (relative risk $=0.50 ; 95 \% \mathrm{CI}, 0.28-0.87)^{29}$ and

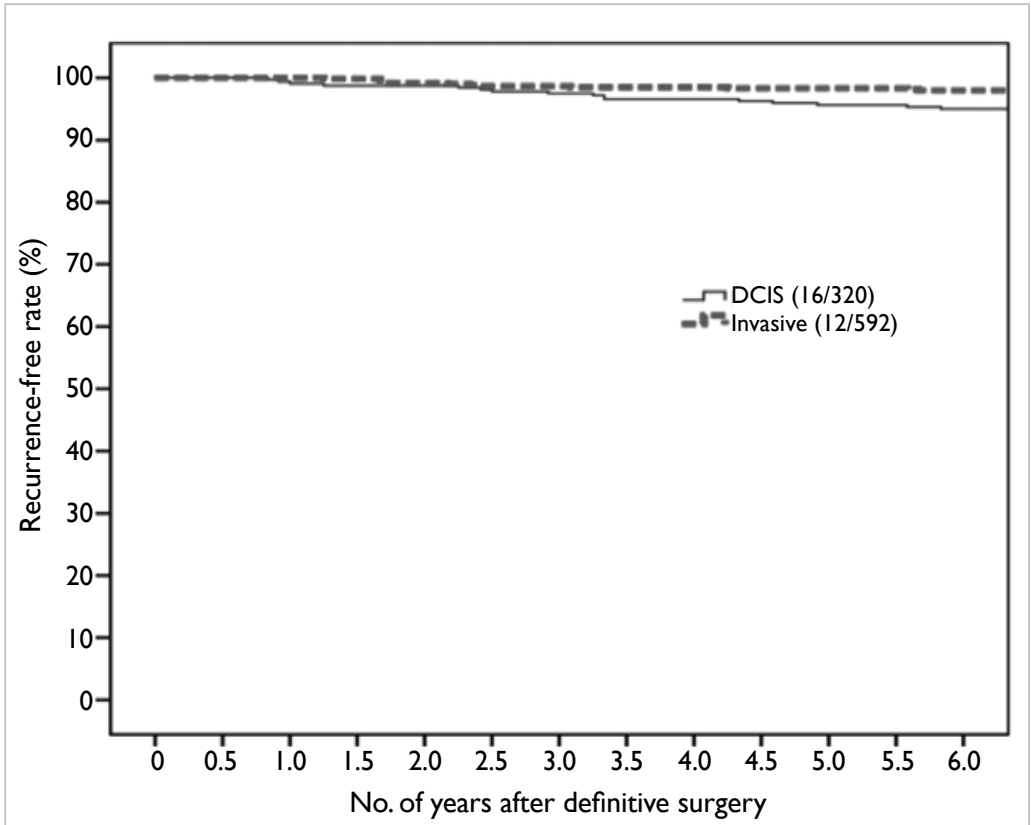

FIG. Actual local recurrence-free rates between ductal carcinoma in situ (DCIS) and invasive breast cancer patients after breast-conserving surgery 
TABLE 4. Comparison of the age of patients with ductal carcinoma in situ between Hong Kong Breast Cancer Registry (HKBCR) and Hong Kong Cancer Registry (HKCR) from 2009 to 2011

\begin{tabular}{|c|c|c|c|c|c|c|}
\hline \multirow{3}{*}{$\begin{array}{l}\text { Age-group } \\
\text { (years) }\end{array}$} & \multicolumn{6}{|c|}{ No. $(\%)$ of patients } \\
\hline & \multicolumn{2}{|c|}{2009} & \multicolumn{2}{|c|}{2010} & \multicolumn{2}{|c|}{2011} \\
\hline & HKBCR & HKCR & HKBCR & HKCR & HKBCR & HKCR \\
\hline$\leq 39$ & $7(7.4)$ & $37(8.3)$ & $6(9.8)$ & $35(7.4)$ & $2(7.4)$ & $37(7.7)$ \\
\hline $40-44$ & $20(21.1)$ & $56(12.6)$ & $8(13.1)$ & $68(14.4)$ & $5(18.5)$ & $66(13.6)$ \\
\hline $45-49$ & $22(23.2)$ & $102(23.0)$ & $11(18.0)$ & $110(23.3)$ & $4(14.8)$ & $103(21.3)$ \\
\hline $50-54$ & $17(17.9)$ & $69(15.6)$ & $17(27.9)$ & 89 (18.9) & $7(25.9)$ & $84(17.4)$ \\
\hline $55-59$ & $15(15.8)$ & $54(12.2)$ & $12(19.7)$ & 49 (10.4) & $6(22.2)$ & $69(14.3)$ \\
\hline $60-64$ & $6(6.3)$ & $38(8.6)$ & $4(6.6)$ & $41(8.7)$ & $2(7.4)$ & $42(8.7)$ \\
\hline $65-69$ & $5(5.3)$ & $25(5.6)$ & 1 (1.6) & $23(4.9)$ & $1(3.7)$ & $30(6.2)$ \\
\hline $70-74$ & $1(1.1)$ & $21(4.7)$ & 0 & $17(3.6)$ & 0 & $22(4.5)$ \\
\hline$\geq 75$ & $2(2.1)$ & $41(9.3)$ & $2(3.2)$ & $40(8.4)$ & 0 & $31(6.4)$ \\
\hline
\end{tabular}

over $60 \%$ of our patients had positive hormonal receptors, less than 20\% DCIS patients in Hong Kong actually received tamoxifen as chemoprevention. ${ }^{30}$ It is likely related to the concern about side-effects (particularly the small risk of endometrial cancer) and the lack of overall survival benefit as shown by the Cochrane systematic review and meta-analysis. ${ }^{29}$ The lack of survival benefit is consistent with the clinical experience that most new lesions detected during follow-up surveillance are highly treatable.

As expected, the local recurrence rate after MTX was very low (0.4\%) in these DCIS patients; it should be noted that $8.7 \%$ had received adjuvant radiotherapy, probably because of close resection margins. For DCIS patients treated by BCS, the crude local recurrence rate in our study was 3.3\% (16 in 320 patients) and was quite similar to the long-term experience in another regional hospital (Pamela Youde Nethersole Eastern Hospital) in Hong Kong. In their analysis of 155 DCIS patients treated by BCS and radiotherapy, after a 10-year median follow-up, the crude local recurrence rate was 5.8\% (unpublished data of Pamela Youde Nethersole Eastern Hospital). Our study did not capture the data on the mode of detection of local recurrences but another local study reported that only $43 \%$ of in-breast recurrences could be first detected by surveillance breast imaging; the rest presented with either nipple discharge or a palpable mass. ${ }^{30}$ Hence, patients should be advised not to become overly dependent on breast imaging to detect early recurrences. Although there were no cancer-related deaths in these DCIS patients, $44 \%$ of local recurrences in this study contained invasive components that may still necessitate systemic treatment in addition to further salvage surgery.

This study provides the first comprehensive analysis of the pattern of care of DCIS in Hong Kong. The strength of this analysis is the comprehensiveness compared with other cancer registries in data collection on epidemiological, pathological, and treatment characteristics for breast cancer. Nonetheless, data from HKBCR might not be representative of all breast cancers in Hong Kong since a higher proportion of patients were recruited from private hospitals or clinics than public hospitals in Hong Kong. Since the data collection was done on a voluntary basis and only started in 2008, some clinical outcome data may be missing (approximately $10 \%$ of DCIS patients) and the follow-up duration remains relatively short, and may not represent the whole local population. There was also a high proportion of missing data for family income in the two internal comparisons. Although the distribution of age at diagnosis in our study did not deviate too far from that reported in the Hong Kong Cancer Registry (a population-based registry; Table 4), older age-groups, especially those aged 70 years and above, were under-represented in the present study. Furthermore, we did not have information on education, occupation, and family income to enable comparison of socio-economic backgrounds.

\section{Conclusions}

Ductal carcinoma in situ in Hong Kong appears to be a more prevalent disease in the higher social classes with a tendency to be managed in the private sector. More than half of DCIS patients can be successfully treated with BCS and the early outcome is excellent and comparable with overseas studies. ${ }^{9,16}$ Further studies are needed to examine the long-term clinical outcome of DCIS in Hong Kong.

\section{Acknowledgements}

The authors thank all of the patients/survivors, doctors, and research staff who have participated in HKBCR to facilitate data collection at clinics and hospitals throughout the territory. The authors 
also acknowledge the following steering committee members: Prof Emily Chan, Dr John Chan, Dr Keeng-Wai Chan, Dr Miranda Chan, Dr Sharon Chan, Dr Foon-Yiu Cheung, Dr Peter Choi, Dr Josette Chor, Ms Yvonne Chua, Ms Doris Kwan, Dr Wing-Hong Kwan, Dr Stephen Law, Dr Simon Leung, Dr Lawrence Li, Dr Janice Tsang, Dr Gary Tse, Mrs Cecilia Tseung, Dr Tung Yuk, Ms Lorna Wong, Dr Ting-Ting Wong, Dr CC Yau, Prof Winnie Yeo, and Prof Benny Zee for providing guidance for the development of the HKBCR.

\section{Declaration}

All authors have disclosed no conflicts of interest.

\section{References}

1. Fortunato L, Poccia I, de Paula U, Santini E. Ductal carcinoma in situ: what can we learn from clinical trials? Int J Surg Oncol 2012;2012:296829.

2. International Agency for Research on Cancer. Globocan 2012: All cancers (excluding non-melanoma skin cancer)estimated incidence, mortality and prevalence worldwide in 2012. Available from: http://globocan.iarc.fr/Pages/ fact_sheets_cancer.aspx. Accessed 2 Apr 2015.

3. Kwong A, Cheung PS, Wong AY, et al. The acceptance and feasibility of breast cancer screening in the East. Breast 2008;17:42-50.

4. Biesheuvel C, Weigel S, Heindel W. Mammography screening: evidence, history and current practice in Germany and other European countries. Breast Care (Basel) 2001;6:104-9.

5. Cheung PS. Global and local status of breast cancer and screening. Paper presented at Hong Kong Breast Cancer Foundation Seminar; 2013 Apr 14; Hong Kong.

6. Hellquist BN, Duffy SW, Abdsaleh S, et al. Effectiveness of population-based service screening with mammography for women ages 40 to 49 years: evaluation of the Swedish Mammography Screening in Young Women (SCRY) cohort. Cancer 2011;117:714-22.

7. Leonard GD, Swain SM. Ductal carcinoma in situ, complexities and challenges. J Natl Cancer Inst 2004;96:906-20.

8. Delaney G, Ung O, Bilous M, Cahill S, Greenberg M, Boyages J. Ductal carcinoma in situ. Part I: definition and diagnosis. Aust N Z J Surg 1997;67:81-93.

9. Chuwa EW, Yeo AW, Koong HN, et al. Early detection of breast cancer through population-based mammographic screening in Asian women: a comparison study between screen-detected and symptomatic breast cancers. Breast J 2009;15:133-9.

10. Morrow M, Strom EA, Bassett LW, et al. Standard for the management of ductal carcinoma in situ of the breast (DCIS). CA Cancer J Clin 2002;52:256-76.

11. Irvine T, Fentiman IS. Biology and treatment of ductal carcinoma in situ. Expert Rev Anticancer Ther 2007;7:135-45.

12. Siziopikou KP. Ductal carcinoma in situ of the breast: current concepts and future directions. Arch Pathol Lab Med 2013;137:462-6.

13. Jiveliouk I, Corn B, Inbar M, Merimsky O. Ductal carcinoma in situ of the breast in Israeli women treated by breast-conserving surgery followed by radiation therapy.
Oncology 2009;76:30-5.

14. Virnig BA, Torchia MT, Jarosek SL, Durham S, Tuttle TM. Data Points \#14: Use of endocrine therapy following diagnosis of ductal carcinoma in situ or early invasive breast cancer. Rockville (MD): Agency for Healthcare Research and Quality; 2011-2012.

15. Tan KB, Lee HY, Putti TC. Ductal carcinoma in situ of the breast in Singapore: recent trends and clinical implications. ANZ J Surg 2002;72:793-7.

16. Chuwa EW, Tan VH, Tan PH, Yong WS, Ho GH, Wong CY. Treatment for ductal carcinoma in situ in an Asian population: outcome and prognostic factors. ANZ J Surg 2008;78:42-8.

17. Mouw KW, Harris JR. Irradiation in early-stage breast cancer: conventional whole-breast, accelerated partialbreast, and accelerated whole-breast strategies compared. Oncology (Williston Park) 2012;26:820-30.

18. Hong Kong Cancer Registry. Leading cancer sites in Hong Kong in 2012. Available from: http://www3.ha.org.hk/ cancereg/rank_2012.pdf. Accessed 15 Jan 2015.

19. Cheung P, Hung WK, Cheung C, et al. Early data from the first population-wide breast cancer-specific registry in Hong Kong. World J Surg 2012;36:723-9.

20. Chua MS, Mok TS, Kwan WH, Yeo W, Zee B. Knowledge, perceptions, and attitudes of Hong Kong Chinese women on screening mammography and early breast cancer management. Breast J 2005;11:52-6.

21. Schouten van der Velden AP, Peeters PH, Koot VC, Hennipman A. Clinical presentation and surgical quality in treatment of ductal carcinoma in situ of the breast. Acta Oncol 2006;45:544-9.

22. Solin LJ, Fourquet A, Vicini FA, et al. Long-term outcome after breast-conservation treatment with radiation for mammographically detected ductal carcinoma in situ of the breast. Cancer 2005;103:1137-46.

23. Habermann EB, Abbot A, Parsons HM, Virnig BA, Al-Refaie WB, Tuttle TM. Are mastectomy rates really increasing in the United States? J Clin Oncol 2010;28:3437-41.

24. Bihrmann K, Jensen A, Olsen AH, et al. Performance of systematic and non-systematic ('opportunistic') screening mammography: a comparative study from Denmark. J Med Screen 2008;15:23-6.

25. Lui CY, Lam HS, Chan LK, et al. Opportunistic breast cancer screening in Hong Kong; a revisit of the Kwong Wah Hospital experience. Hong Kong Med J 2007;13:106-13.

26. Fisher B, Dignam J, Wolmark N, et al. Lumpectomy and radiation therapy for the treatment of intraductal breast cancer: findings from National Surgical Adjuvant Breast and Bowel Project B-17. J Clin Oncol 1998;16:441-52.

27. Silverstein MJ, Lagios MD, Craig PH, et al. A prognostic index for ductal carcinoma in situ of the breast. Cancer 1996;77:2267-74.

28. de Mascarel I, Bonichon F, MacGrogan G, et al. Application of the Van Nuys prognostic index in a retrospective series of 367 ductal carcinomas in situ of the breast examined by serial macroscopic sectioning: practical considerations. Breast Cancer Res Treat 2000;61:151-9.

29. Staley H, McCallum I, Bruce J. Postoperative tamoxifen for ductal carcinoma in situ: Cochrane systematic review and meta-analysis. Breast 2014;23:546-51.

30. Yau TK, Sze H, Soong IS, et al. Surveillance mammography after breast conservation therapy in Hong Kong: effectiveness and feasibility of risk-adapted approach. Breast 2008;17:132-7. 